\title{
Article
}

\section{High Q Resonant Graphene Absorber with Lossless Phase Change Material $\mathrm{Sb}_{2} \mathrm{~S}_{3}$}

\author{
Qi Meng ${ }^{1,2}\left(\mathbb{D}\right.$, Xingqiao Chen ${ }^{1,2}$, Wei Xu ${ }^{1,2}$, Zhihong Zhu ${ }^{1,2}$, Shiqiao Qin ${ }^{1,2}$, Jianfa Zhang ${ }^{1,2, *(\mathbb{D})}$ \\ and Xiaodong Yuan ${ }^{1,2}$ \\ 1 College of Advanced Interdisciplinary Studies, National University of Defense Technology, \\ Changsha 410073, China; Monky19@163.com (Q.M.); chenxingqiao14@nudt.edu.cn (X.C.); \\ weixu08a@163.com (W.X.); zzhwcx@163.com (Z.Z.); sqqin8@nudt.edu.cn (S.Q.); x.d.yuan@163.com (X.Y.) \\ 2 Hunan Provincial Key Laboratory of Novel Nano-Optoelectronic Information Materials and Devices, \\ National University of Defense Technology, Changsha 410073, China \\ * Correspondence: jfzhang85@nudt.edu.cn
}

check for updates

Citation: Meng, Q.; Chen, X.; Xu, W.; Zhu, Z.; Qin, S.; Zhang, J.; Yuan, X. High $Q$ Resonant Graphene Absorber with Lossless Phase Change Material $\mathrm{Sb}_{2} \mathrm{~S}_{3}$. Nanomaterials 2021, 11, 2820. https://doi.org/10.3390/nano11112820

Academic Editors: Konstantins Jefimovs and Werner Blau

Received: 27 August 2021

Accepted: 20 October 2021

Published: 24 October 2021

Publisher's Note: MDPI stays neutral with regard to jurisdictional claims in published maps and institutional affiliations.

Copyright: (C) 2021 by the authors. Licensee MDPI, Basel, Switzerland. This article is an open access article distributed under the terms and conditions of the Creative Commons Attribution (CC BY) license (https:/ / creativecommons.org/licenses/by/ $4.0 /)$.

\begin{abstract}
Graphene absorbers have attracted lots of interest in recent years. They provide huge potential for applications such as photodetectors, modulators, and thermal emitters. In this letter, we design a high-quality $(\mathrm{Q})$ factor resonant graphene absorber based on the phase change material $\mathrm{Sb}_{2} \mathrm{~S}_{3}$. In the proposed structure, a refractive index grating is formed at the subwavelength scale due to the periodical distributions of amorphous and crystalline states, and the structure is intrinsically flat. The numerical simulation shows that nearly $100 \%$ absorption can be achieved at the wavelength of $1550 \mathrm{~nm}$, and the $\mathrm{Q}$ factor is more than hundreds due to the loss-less value of $\mathrm{Sb}_{2} \mathrm{~S}_{3}$ in the near-infrared region. The absorption spectra can be engineered by changing the crystallization fraction of the $\mathrm{Sb}_{2} \mathrm{~S}_{3}$ as well as by varying the duty cycle of the grating, which can be employed not only to switch the resonant wavelength but also to achieve resonances with higher $\mathrm{Q}$ factors. This provides a promising method for realizing integrated graphene optoelectronic devices with the desired functionalities.
\end{abstract}

Keywords: graphene absorbers; phase change material; high $\mathrm{Q}$

\section{Introduction}

Graphene absorbers have attracted lots of interest in recent years [1-3]. They provide huge potential for applications such as photodetectors [4], modulators [5-8], and thermal emitters $[9,10]$. Meanwhile, high-Q planar resonator structures have been extensively studied in the past few years. Various structures have been studied to achieve high $Q$ resonances, including photonic crystals [11-13], dielectric metasurfaces [14,15], nanocavities [16,17] and guided mode resonance structures [18-20] (GMRs). Such types of high Q photonic devices provide a promising future for novel photonic and optoelectronic devices, such as thermal emitters [21,22], ultrathin mirrors [23,24], ultrafast photodetectors [25,26], polarization devices $[27,28]$ and nonlinear optics $[20,29]$. Thus, the realization of high $Q$ resonant graphene absorbers is of particular importance for many applications.

Phase change materials (PCM), such as $\mathrm{Ge}_{2} \mathrm{Sb}_{2} \mathrm{Te}_{2}(\mathrm{GST})$ and $\mathrm{VO}_{2}$, have has been used in optically tunable nanophotonic devices for a long time [30-32], such as thermal camouflage [33], dynamic color display [34-36], beam steering [37], and light modulation [38-41]. Previous work has been able to write, erase, and rewrite two-dimensional binary or gray-scale functional patterns into nano-scale GST films through customized lasers, to induce local refractive index changes and construct nanophotonic devices [42,43]. Electrode heating can also be applied to write and erase the patterns in GST, achieving a polarization-insensitive phase gradient metasurface [44]. However, the inherent absorption of most previous phase change materials, such as GST and $\mathrm{VO}_{2}$, in the near-infrared and 
visible light bands limits their resonant $Q$ factors and, thus, the performances in many photonic devices.

In this study, we propose a high $\mathrm{Q}$ rewriteable resonant graphene absorber with the phase change material antimony trisulphide $\left(\mathrm{Sb}_{2} \mathrm{~S}_{3}\right)$.The absorption of $\mathrm{Sb}_{2} \mathrm{~S}_{3}$ in the near-infrared is zero, which promises a relatively high $Q$ factor for the absorber. We can construct refractive index grating in the $\mathrm{Sb}_{2} \mathrm{~S}_{3}$ layer by local crystallization (i.e., with laser or ion beam), which greatly simplifies the processing of photonic devices. We can also easily "write" or "erase" the grating layer to adjust the structural parameters of photonic devices. Numerical simulations indicate that the graphene integrated $\mathrm{Sb}_{2} \mathrm{~S}_{3}$ absorber achieves nearly $100 \%$ absorption at $1547.9 \mathrm{~nm}$, with the spectral linewidths (full width at half maximum, FWHM) of $2.4 \mathrm{~nm}$, corresponding a high $\mathrm{Q}$ factor of 644 . We can engineer the absorption spectrum by adjusting the duty cycle or crystalline fraction, to tune the resonant wavelength or obtain a much higher $\mathrm{Q}$ factor.

\section{Result and Discussion}

Local heating, laser illumination, or ion beam irradiation can be used to induce the phase transition of the $\mathrm{Sb}_{2} \mathrm{~S}_{3}$ film, thus make a grating layer with crystalline $\mathrm{Sb}_{2} \mathrm{~S}_{3}$ $\left(\mathrm{c}_{-} \mathrm{Sb}_{2} \mathrm{~S}_{3}\right)$ and amorphous $\mathrm{Sb}_{2} \mathrm{~S}_{3}\left(\mathrm{a}_{-} \mathrm{Sb}_{2} \mathrm{~S}_{3}\right)$. Here, it should be indicated that the graphene can survive under the light intensities of tens of thousands $\mathrm{GW} / \mathrm{m}^{2}$ [45], and the pulse intensity required to accomplish transition is about $10 \mathrm{GW} / \mathrm{m}^{2}$ [46], which is much lower than that of destroying a monolayer graphene. Moreover, for the ion beam, the graphene can be transferred to the top of the structure after the grating is produced to avoid damage. Figure $1 \mathrm{a}$ is the schematic of the integrated $\mathrm{Sb}_{2} \mathrm{~S}_{3}$ absorber. From top to bottom, is the monolayer graphene, $\mathrm{Sb}_{2} \mathrm{~S}_{3}$ grating, a silicon ( $\mathrm{Si}$ ) waveguide layer, a silica $\left(\mathrm{SiO}_{2}\right)$ substrate layer and an $\mathrm{Au}$ mirror, with the thickness of graphene, $\mathrm{Sb}_{2} \mathrm{~S}_{3}, \mathrm{Si}, \mathrm{SiO}_{2}$ and $\mathrm{Au}$ is $0.34 \mathrm{~nm}$, $40 \mathrm{~nm}, 205 \mathrm{~nm}, 380 \mathrm{~nm}$ and $150 \mathrm{~nm}$, respectively. The sideview of the $\mathrm{Sb}_{2} \mathrm{~S}_{3}$ absorber is shown in Figure 1b, and the period of the absorber is $p=550 \mathrm{~nm}$, and width of c_- $\mathrm{Sb}_{2} \mathrm{~S}_{3}$ is $w=f \times p$, where $f=0.5$ is the duty cycle of the absorber.

(a)

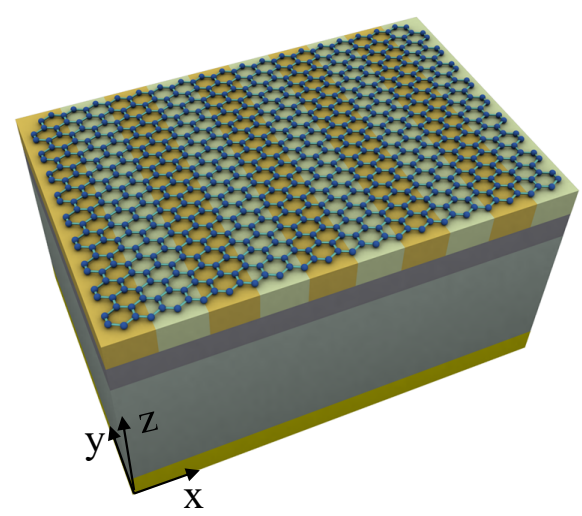

(b)

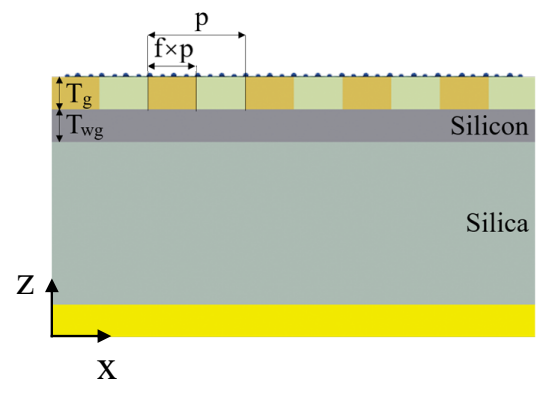

Figure 1. Schematic of the graphene absorber with $\mathrm{Sb}_{2} \mathrm{~S}_{3}$. (a) Schematic of graphene absorber with $\mathrm{Sb}_{2} \mathrm{~S}_{3}$. From top to bottom, is the graphene, $\mathrm{Sb}_{2} \mathrm{~S}_{3}$ grating, a silicon waveguide layer, a silica substrate layer, and an Au mirror. The structure is intrinsically flat and no etching process is needed. (b) Sideview of the proposed absorber.

The numerical simulations are conducted in a fully three-dimensional finite element technology (in COMSOL Multiphysics). Since our structure is assumed to be "infinitely extending" in the y direction, we use a two-dimensional model for simulations ( $\mathrm{x}-\mathrm{z}$ plane). We used Floquet periodic boundary conditions in the $x$-direction, and port boundary conditions at the top and bottom of the model along the z-direction. In the simulation, $\mathrm{SiO}_{2}$ and $\mathrm{Si}$ are regarded as a lossless medium in the near-infrared, with a refractive 
index of $\mathrm{n}_{\mathrm{SiO}_{2}}=1.45$ and $\mathrm{n}_{\mathrm{Si}}=3.42$. The permittivity of gold was described by the Drude model with plasma frequency $\omega_{p}=1.37 \times 10^{-16} \mathrm{~s}^{-1}$ and the damping constant $\omega_{t}=12.15 \times 10^{-13} \mathrm{~s}^{-1}$, which was three times larger than the bulk value. The complex refractive indices of $c_{-} \mathrm{Sb}_{2} \mathrm{~S}_{3} \mathrm{n}_{\mathrm{c}}$ and $\mathrm{a}_{-} \mathrm{Sb}_{2} \mathrm{~S}_{3} \mathrm{n}_{\mathrm{a}}$ are taken from experimental measurements [46], and the absorption of $\mathrm{Sb}_{2} \mathrm{~S}_{3}$ is zero in the near-infrared region. For example, the complex refractive indices of $c_{-} \mathrm{Sb}_{2} \mathrm{~S}_{3}$ and $\mathrm{a}_{-} \mathrm{Sb}_{2} \mathrm{~S}_{3}$ at the wavelength of $1550 \mathrm{~nm}$ are $\mathrm{n}_{\mathrm{c}}=3.308+0 \mathrm{i}$ and $\mathrm{n}_{\mathrm{a}}=2.712+0 \mathrm{i}$, respectively. Furthermore, Graphene is defined by a conductivity model [47]:

$$
\begin{aligned}
\sigma_{\omega} & =\sigma_{\text {intra }}(\omega)+\sigma_{\text {inter }}(\omega) \\
\sigma_{\text {intra }}(\omega) & =\frac{2 e^{2} k_{B} T}{\pi \hbar^{2}} \frac{i}{\omega+i \tau^{-1}} \ln \left[2 \cosh \left(\frac{E_{f}}{2 k_{B} T}\right)\right] \\
\sigma_{\text {inter }}(\omega) & =\frac{e^{2}}{4 \hbar}\left[\frac{1}{2}+\frac{1}{\pi} \arctan \left(\frac{\hbar \omega-2 E_{f}}{2 k_{B} T}\right)-\frac{i}{2 \pi} \ln \frac{\left(\hbar \omega+2 E_{f}\right)^{2}}{\left(\hbar \omega-2 E_{f}\right)^{2}+4\left(k_{B} T\right)^{2}}\right]
\end{aligned}
$$

where $\hbar$ is the reduced Planck constant, $k_{B}$ is the Boltzmann constant. Here, we have $E_{f} \sim 0 e v, \tau=10^{-14} \mathrm{~s}$, and $T=300 \mathrm{~K}$ for the Fermi level, relaxation time, and temperature, respectively. The relation between surface conductivity and permittivity of graphene is:

$$
\varepsilon_{r}=1+i \frac{\sigma}{\varepsilon_{0} \omega d}
$$

Here, $\sigma$ is the surface conductivity and $d$ is the thickness of graphene. For the graphene monolayer, we have $d=0.34 \mathrm{~nm}, \omega$ is the angular frequency, and $\varepsilon_{0}$ is the vacuum permittivity, respectively.

Figure $2 \mathrm{a}$ shows the simulated absorption spectra of the graphene-integrated $\mathrm{Sb}_{2} \mathrm{~S}_{3}$ absorber. For transverse electric (TE) polarized light at normal incidence, a typical high $\mathrm{Q}$ guided mode resonance is excited around the wavelength of $1547.9 \mathrm{~nm}$, with a resonant absorption of nearly $100 \%$ at the peak (the transverse magnetic (TM) mode can also excite the resonances in the studied structure, but at different wavelengths). An integration of resistive losses in the numerical simulations show that only an ignorable part of the light is absorbed by $\mathrm{Au}$ (the green dotted lined), while over $99 \%$ of the light is absorbed by the graphene (the black dotted lined). Owing to the existence of the $\mathrm{SiO}_{2}$ substrate layer, the interplay of the GMR resonance of the $\mathrm{Sb}_{2} \mathrm{~S}_{3}$ and the Fabry-Pérot (F-P) effect on the cavity greatly enhances the absorption of the graphene [20]. Figure $2 b$ is the distributions of the electric field in the $y$-direction at the resonance wavelength of $1547.9 \mathrm{~nm}$, which means that most of the energy is trapped in the waveguide.

The excitation of the guided mode resonance can be controlled by changing the geometric parameters of the structure (such as period and duty cycle), as mentioned above. We now fix the period of the grating, and tune the absorption spectra by changing the duty cycle. As shown in the Figure 3, as the duty cycle decreases from $f=0.5$ to $f=0.1$, the resonance wavelength shifts from $1547.9 \mathrm{~nm}$ to $1542.4 \mathrm{~nm}$ and the maximum resonant absorption decreases from $99.83 \%$ to $40.88 \%$. At the same time, the spectral linewidths (FWHM) decrease from $2.4 \mathrm{~nm}$ to $1.4 \mathrm{~nm}$, corresponding to an increase of the $\mathrm{Q}$ factor from 644 to $1101\left(\mathrm{Q}=\lambda_{r} / \mathrm{FWHM}, \lambda_{r}\right.$ is the resonant wavelength). Such phenomena can be explained by the concept of critical coupling derived from the coupled mode theory [48], that is, when the mode leakage rate $\gamma$ is equal to the absorption rate $\alpha$ of the structure, the perfect absorption occurs. In this work, the perfect absorber is designed by integrating graphene with a resonator illuminated from one side, where a back mirror is used to completely block the transmission. Here, the mode leakage rate denotes the energy coupled in the structure, while the absorption rate $\alpha$ is determined by the graphene absorption coefficient (a constant) and the field intensity in the graphene layer. The decrease of duty cycle reduces the effective refractive index of the $\mathrm{Sb}_{2} \mathrm{~S}_{3}$ grating layer, thus introducing the blueshift and the decrease of the leakage rate $\gamma$. As the leakage 
rate $\gamma$ is no longer equal to the absorption rate $\alpha$, the absorption peak decreases for the mismatch of the critical coupling. Previous work has indicated that the linewidth (FWHM) is proportional to $(\gamma+\alpha)$ [48], the FWHM therefore decreases as that of the leakage rate $\gamma$.

(a)

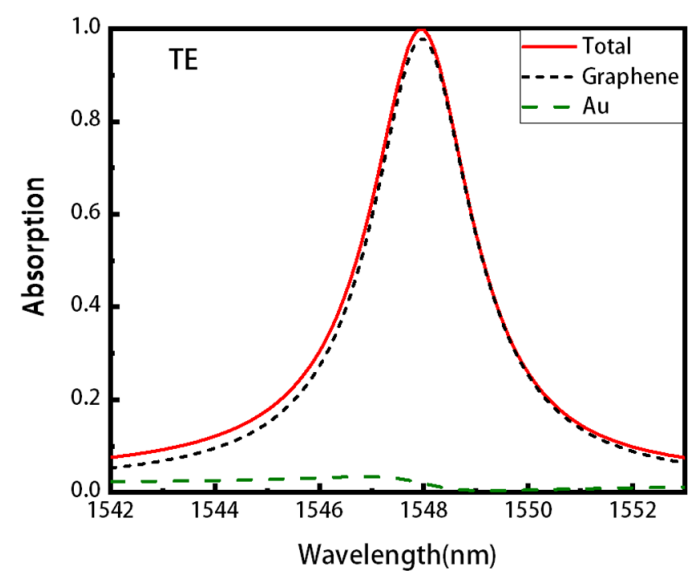

(b)

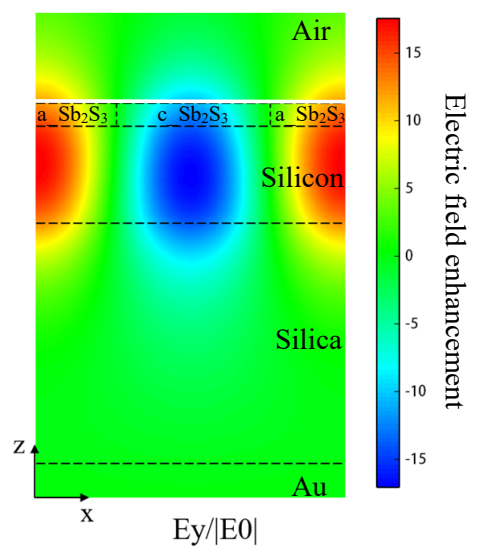

Figure 2. The simulation results of the proposed graphene absorber. (a) Absorption spectra for TE (y-polarized) polarization. The structure has near $100 \%$ absorption at $1547.9 \mathrm{~nm}$, and the absorption of graphene reaches $99 \%$. (b) The distributions of the normalized electric field in the y-direction at the resonance wavelength of $1547.9 \mathrm{~nm}$.

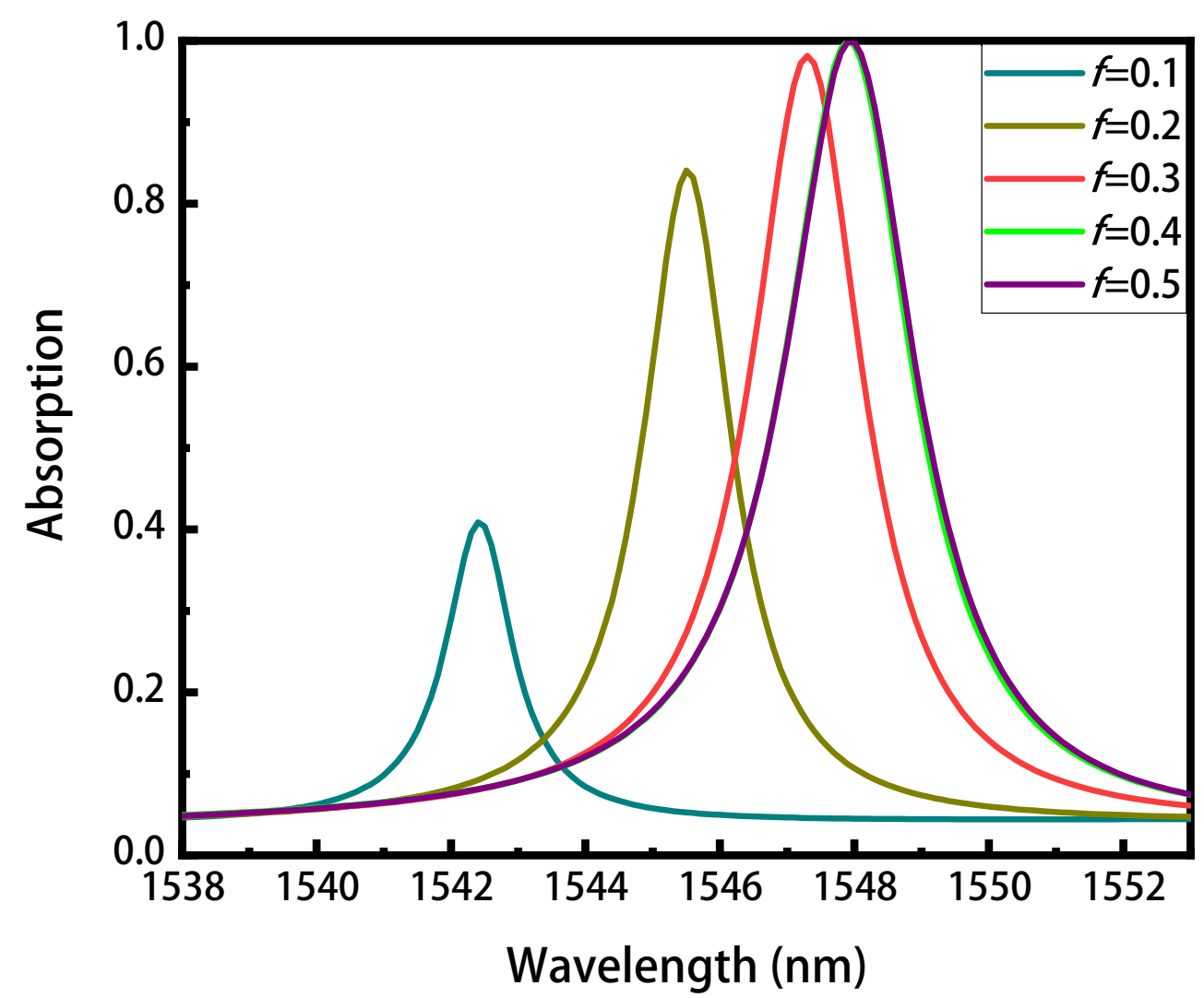

Figure 3. The absorption spectra of the graphene absorber with different duty cycles. As the duty cycle decreases from 0.5 to 0.1 , the peak absorption and the linewidth decrease.

This type of mismatch results from the decrease of the mode leakage rate $\gamma$ as the duty cycle $f$ is reducing, and it can be avoided so long as the effective absorption rate of graphene $\alpha$ decreases, where the critical coupling condition meets again. As shown in 
the Figure 4a, we now add a spacer (coating) layer $\mathrm{SiO}_{2}$ between the $\mathrm{Sb}_{2} \mathrm{~S}_{3}$ grating and graphene, thus moving the graphene away from the waveguide layer where most of the enhanced electric field is localized. As the effective absorption rate of graphene decreases, we can achieve critical coupling and perfect absorption for smaller duty cycles. Taking duty cycle $f=0.1$ and $f=0.2$ as the example, as shown in the Figure $4 \mathrm{~b}$, with the thickness of the spacer layer $\mathrm{t}=115 \mathrm{~nm}$ and $\mathrm{t}=50 \mathrm{~nm}$, respectively; thus, the absorber structure achieves perfect absorption in both cases. The linewidth (FWHM) of $f=0.1$ and $f=0.2$ are $0.23 \mathrm{~nm}$ and $0.88 \mathrm{~nm}$, corresponding to high $Q$ of 6726 and 1760, respectively, which is the consequence of the decrease of the mode leakage rate $\gamma$ and absorption rate $\alpha$.

(a)

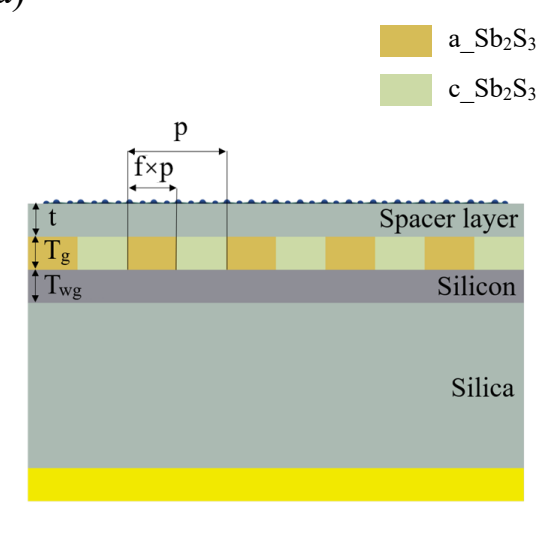

(b)

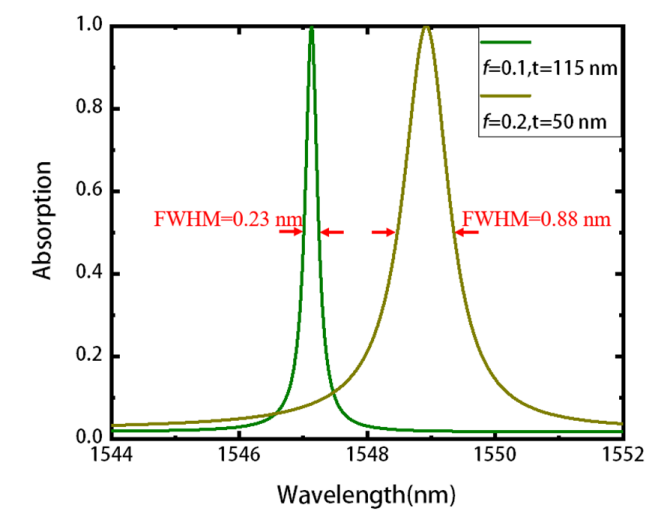

Figure 4. Engineered perfect absorption with high $\mathrm{Q}$ and narrow band. (a) Schematic of the absorber with a $\mathrm{SiO}_{2}$ spacer layer between graphene and the phase change layer. As the duty cycle varies, one can change the thickness of the spacer layer to meet the critical coupling condition and, thus, realize perfect absorption. (b) The structure achieves nearly $100 \%$ absorption again for the duty cycle $f=0.1$ and $f=0.2$ with $115 \mathrm{~nm} \mathrm{SiO} 2$ and $50 \mathrm{~nm} \mathrm{SiO}_{2}$, respectively.

A previous work has demonstrated that there is an intermediate state of $\mathrm{Sb}_{2} \mathrm{~S}_{3}$ between a_S $b_{2} S_{3}$ and $c_{-} \mathrm{Sb}_{2} \mathrm{~S}_{3}$, and has been able to use different power femtosecond laser pulses to control the crystallization fraction of $\mathrm{Sb}_{2} \mathrm{~S}_{3}$ [35]. The effective dielectric constant of c__ $\mathrm{Sb}_{2} \mathrm{~S}_{3}$ can be obtained by the Lorenz-Lorentz relationship along with the Bruggeman mix rule [49]:

$$
\frac{\varepsilon_{e f f}(\lambda)-1}{\varepsilon_{e f f}(\lambda)+2}=\eta \times \frac{\varepsilon_{\mathrm{c}_{2} \mathrm{Sb}_{2} \mathrm{~S}_{3}}(\lambda)-1}{\varepsilon_{\mathrm{c}_{-} \mathrm{Sb}_{2} \mathrm{~S}_{3}}(\lambda)+2}+(1-\eta) \times \frac{\varepsilon_{\mathrm{a}_{-} \mathrm{Sb}_{2} \mathrm{~S}_{3}}(\lambda)-1}{\varepsilon_{\mathrm{a}_{-} \mathrm{Sb}_{2} \mathrm{~S}_{3}}(\lambda)+2}
$$

where $\varepsilon_{\mathrm{C}_{-} \mathrm{Sb}_{2} \mathrm{~S}_{3}}(\lambda)$ and $\varepsilon_{\mathrm{a}_{1} \mathrm{Sb}_{2} \mathrm{~S}_{3}}(\lambda)$ are the wavelength-dependent permittivity of crystalline and amorphous $\mathrm{Sb}_{2} \mathrm{~S}_{3}$, respectively, and $\eta$ is the crystalline fraction of $\mathrm{c}_{-} \mathrm{Sb}_{2} \mathrm{~S}_{3}$. Now, we fixed the duty cycle $f=0.5$ and vary the crystallization fraction of $\mathrm{c}_{-} \mathrm{Sb}_{2} \mathrm{~S}_{3}$. The absorption spectra with the different crystallization fractions are shown in Figure 5. The decrease of the crystallization fraction causes a similar influence on the absorption as the decrease of the duty ratio, where the resonance wavelength shifts from $1547.9 \mathrm{~nm}$ to $1540.0 \mathrm{~nm}$ and the maximum resonant absorption decreases from $99.83 \%$ to $14.25 \%$. Furthermore, the spectral linewidths (FWHM) decrease from $2.4 \mathrm{~nm}$ to $1.6 \mathrm{~nm}$, corresponding to an increase of $\mathrm{Q}$ factor from 644 to 962 . 


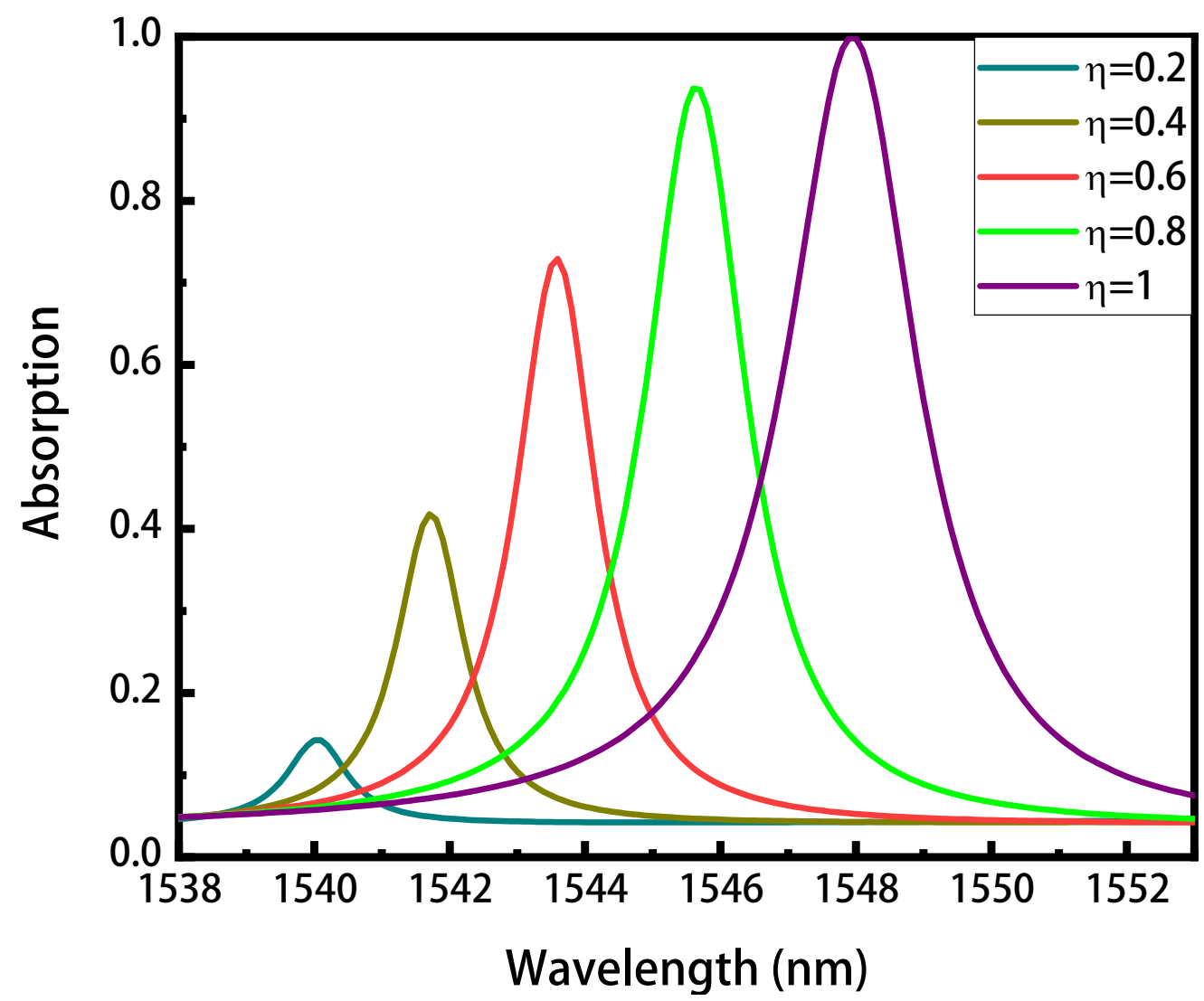

Figure 5. The absorption spectra of the graphene absorber with different crystalline fractions of the $\mathrm{Sb}_{2} \mathrm{~S}_{3}$ grating (with duty cycle fixed at $f=0.5$ ).

To investigate the influence of the boundary between amorphous and crystalline PCM, we also set a linear graded-index with the width of $100 \mathrm{~nm}$ at each boundary between amorphous and crystalline $\mathrm{Sb}_{2} \mathrm{~S}_{3}$, with other parameters kept the same as that of Figure 2 (see the Figure 6a). As is shown in Figure 6b, a similar sharp resonance is observed near the telecom wavelength range. The absorption decreases to $87 \%$, while FWHM decreases from $2.40 \mathrm{~nm}$ to $1.72 \mathrm{~nm}$, with a $\mathrm{Q}$ factor of 896. Those changes can be easily understood, as a linear graded-index boundary means a decrease of the refractive index contrast and the mode leakage rate $\gamma$. To achieve perfect absorption again, we can add a spacer layer as that of Figure 4 to reduce the absorption rate $\alpha$. After adding a $40 \mathrm{~nm}$ spacer layer, the resonant grating absorber achieves nearly $100 \%$ absorption again, with FWHM $=1.04 \mathrm{~nm}$, corresponding to a much higher $Q$ factor of 1485 (see the Figure 6c).

Figure 7 illustrates the angular dependence of the graphene absorber (the parameters kept the same as that of Figure 2). Different from the metamaterials or plasmonic absorbers with localized resonances, whose angular dependence is generally weak. The guide mode resonant (GMR) grating-based absorber here is sensitive to the incident angle, as shown in the figure, with the incident angle increased from 0 to 1 degree, the single absorption peak split into two, and therefore, the greater the angle, the greater the distance between them. This angle-dependence comes from phase-matching and has been well studied [50]. It can be applied to directional thermal emitting [51], optical filtering [52], angle sensorinfg [53] and other applications. 
(a)

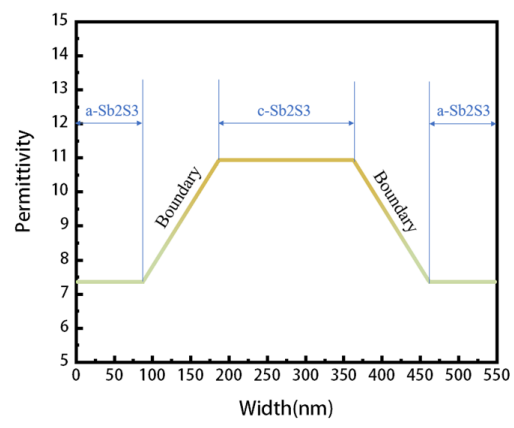

(b)

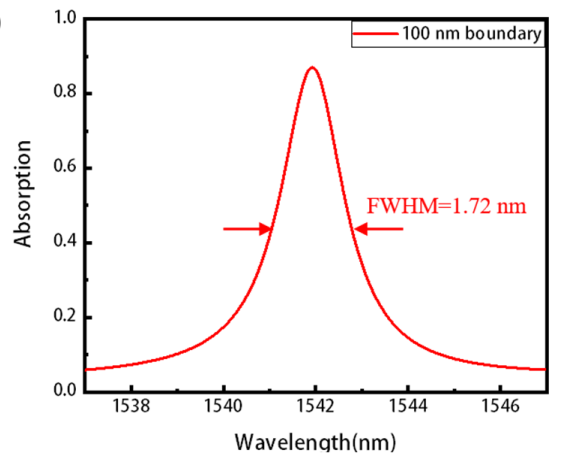

(c)

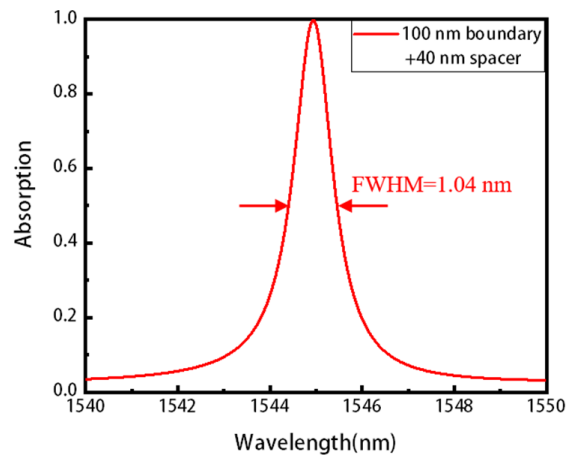

Figure 6. Considering the influence of the boundary between amorphous and crystalline $\mathrm{Sb}_{2} \mathrm{~S}_{3}$. (a) The linear graded index with a width of $100 \mathrm{~nm}$ at each boundary between amorphous and crystalline $\mathrm{Sb}_{2} \mathrm{~S}_{3}$. (b) The changes of absorption and $\mathrm{Q}$ after considering graded index boundary. (c) Achieving perfect absorption again after adding a spacer layer.

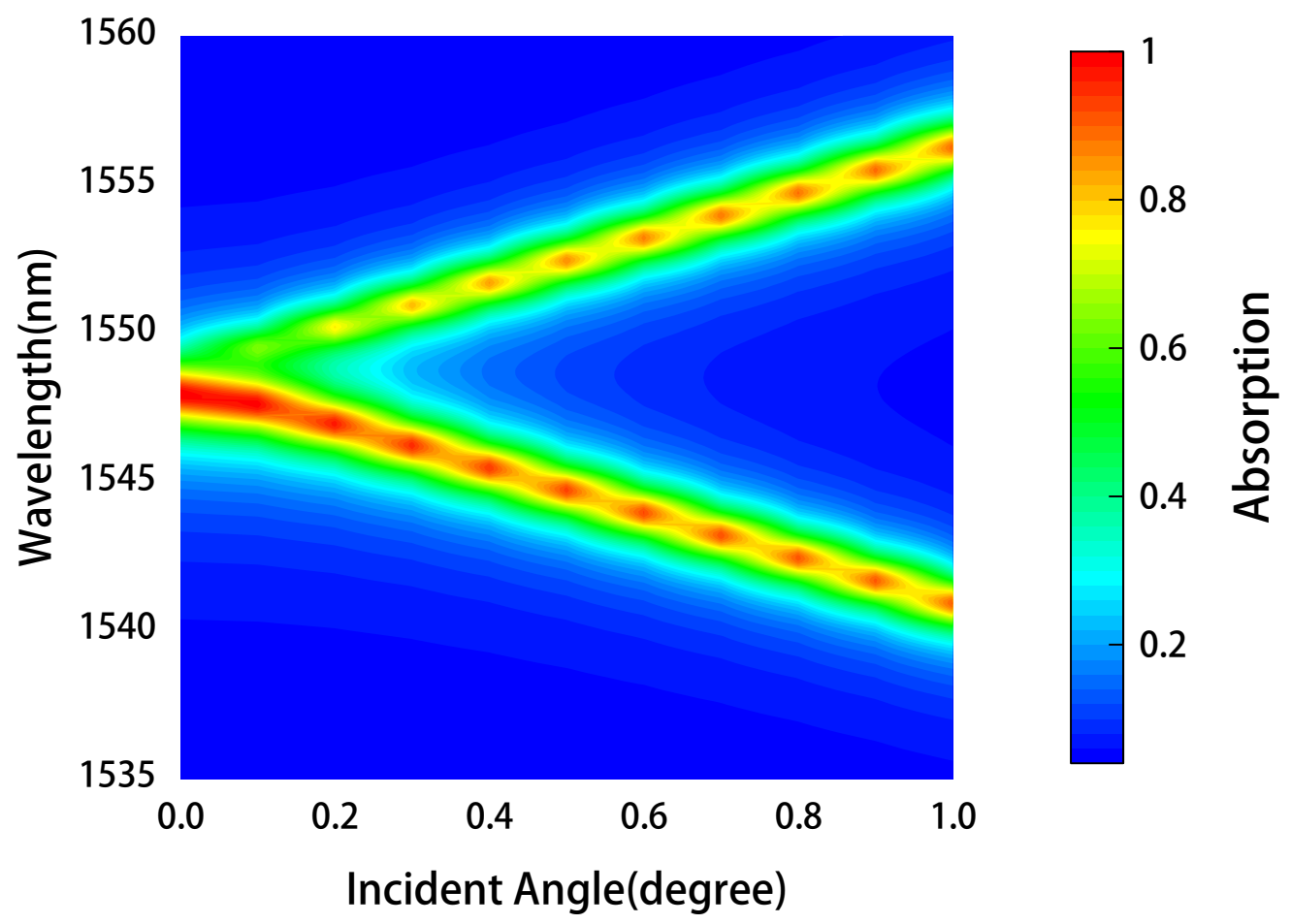

Figure 7. Angular dependence of the graphene absorber structure for TE polarization, the parameters of the structure are the same as those of Figure 2. And the calculated angle ranges from 0 to 1 degree.

\section{Conclusions}

In all, we have proposed a type of subwavelength resonant graphene absorber based on the phase change material $\mathrm{Sb}_{2} \mathrm{~S}_{3}$. The proposed structure is intrinsically flat, which 
is different from most previously demonstrated graphene absorbers in the near-infrared range. We can deposit the phase change material $\mathrm{Sb}_{2} \mathrm{~S}_{3}$ on the $\mathrm{Si}$ and then use customized laser pulses to realize the required structure (e.g., the grating structure). Other methods, such as electrothermal switching [54,55], could also be applied to induce the crystallization and amorphization of phase change materials. The ultralow loss of $\mathrm{Sb}_{2} \mathrm{~S}_{3}$ enables us to realize high $\mathrm{Q}$ factors up to thousands in the proposed structure. To achieve the high $\mathrm{Q}$ resonances, we have employed a classical guided-mode resonant grating structure, which generally consists of a grating layer, a waveguide layer with a relatively high refractive index, and a substrate. Here, the PCM with periodical distributions of amorphous and crystalline states works as a refractive index grating. Silica is the most widely used material in a semiconductor and is also widely used in photonics. It has a high refractive index and low loss at the studied telecom wavelength range. Thus, a Si layer is chosen as the waveguide layer. $\mathrm{SiO}_{2}$ with a relatively low refractive index and low loss was chosen as the substrate, and a reflective gold layer is used to block the transmission for perfect absorption. The thickness of the $\mathrm{PCM}, \mathrm{Si}$, and $\mathrm{SiO}_{2}$ has been optimized to realize the high-Q resonances and satisfy the critical coupling conditions for perfect absorption. Simulation results demonstrate that the absorber achieves nearly $100 \%$ absorption at $1547.9 \mathrm{~nm}$, with linewidths of $2.4 \mathrm{~nm}$, corresponding to a high $\mathrm{Q}$ factor of 644 . Besides, we can continuously tune the absorption spectra not only by adjusting the duty cycle but also by changing the crystalline fraction. Resonant perfect absorption with a much higher $Q$ factor up to 6726 is numerically demonstrated with a smaller duty cycle $f=0.1$ and a spacing layer between the phase change material-based grating and graphene to reduce both the coupling rate and the absorption rate. This type of high $Q$ resonant of two-dimension materials of the integrated phase change metadevice can also be applied to other atomical materials, such as $\mathrm{MoS}_{2}$ and $\mathrm{WS}_{2}$, whose absorption at visible and near-infrared wavelengths is considerable [56]. This provides a promising method for realizing integrated graphene and other two-dimensional material optoelectronic devices with desired functionalities such as photodetection, light generation, spatial light modulation, and others [57].

Author Contributions: J.Z. conceived the idea and supervised the study. Q.M., X.C., J.Z. and W.X. conducted the numerical simulations. Q.M. and J.Z. wrote the manuscript. Q.M., X.C., J.Z., W.X., Z.Z., X.Y. and S.Q. contributed to the data analysis. All authors have read and agreed to the published version of the manuscript.

Funding: This work was supported by the Postgraduate Scientific Research Innovation Project of Hunan Province (QL20210006); the National Natural ScienceFoundation of China (11674396) and the Science and Technology Planning Project of Hunan Province (2018JJ1033 and 2017RS303)

Data Availability Statement: The data presented in this study are available on request from the corresponding author.

Conflicts of Interest: The authors declare no conflict of interest.

\section{References}

1. Grande, M.; Vincenti, M.A.; Stomeo, T.; Bianco, G.V.; de Ceglia, D.; Aközbek, N.; Petruzzelli, V.; Bruno, G.; Vittorio, M.D.; Scalora, M.; et al. Graphene-based absorber exploiting guided mode resonances in one-dimensional gratings. Opt. Express 2014, 22, 31511-31519. [CrossRef]

2. Grande, M.; Vincenti, M.A.; Stomeo, T.; Bianco, G.V.; de Ceglia, D.; Aközbek, N.; Petruzzelli, V.; Bruno, G.; Vittorio, M.D.; Scalora, M.; et al. Graphene-based perfect optical absorbers harnessing guided mode resonances. Opt. Express 2015, 23, 21032-21042. [CrossRef]

3. Guo, C.C.; Zhu, Z.H.; Yuan, X.D.; Ye, W.M.; Liu, K.; Zhang, J.F.; Xu, W.; Qin, S.Q. Experimental Demonstration of Total Absorption over 99\% in the Near Infrared for Monolayer-Graphene-Based Subwavelength Structures. Adv. Opt. Mater. 2016, 4, 1955-1960. [CrossRef]

4. Liu, Y.; Cheng, R.; Liao, L.; Zhou, H.; Bai, J.; Liu, G.; Liu, L.; Huang, Y.; Duan, X. Plasmon resonance enhanced multicolour photodetection by graphene. Nat. Commun. 2011, 2, 579. [CrossRef] [PubMed]

5. Liu, M.; Yin, X.; Ulin-Avila, E.; Geng, B.; Zentgraf, T.; Ju, L.; Wang, F.; Zhang, X. A graphene-based broadband optical modulator. Nature 2011, 474, 64-67. [CrossRef] [PubMed] 
6. Phare, C.T.; Lee, Y.D.; Cardenas, J.; Lipson, M. Graphene electro-optic modulator with 30GHz bandwidth. Nat. Photonics 2015, 9, 511-514. [CrossRef]

7. Chen, J.; Chen, S.; Gu, P.; Yan, Z.; Tang, C.; Xu, Z.; Liu, B.; Liu, Z. Electrically modulating and switching infrared absorption of monolayer graphene in metamaterials. Carbon 2020, 162, 187-194. [CrossRef]

8. Hemmatyar, O.; Rahmani, B.; Bagheri, A.; Khavasi, A. Phase Resonance Tuning and Multi-Band Absorption Via GrapheneCovered Compound Metallic Gratings. IEEE J. Quantum Electron. 2017, 53, 1-10. [CrossRef]

9. Kim, Y.D.; Kim, H.; Cho, Y.; Ryoo, J.H.; Park, C.H.; Kim, P.; Kim, Y.S.; Lee, S.; Li, Y.; Park, S.N.; et al. Bright visible light emission from graphene. Nat. Nanotechnol. 2015, 10, 676-681. [CrossRef]

10. Luo, F.; Fan, Y.; Peng, G.; Xu, S.; Yang, Y.; Yuan, K.; Liu, J.; Ma, W.; Xu, W.; Zhu, Z.H.; et al. Graphene Thermal Emitter with Enhanced Joule Heating and Localized Light Emission in Air. ACS Photonics 2019, 6, 2117-2125. [CrossRef]

11. Yoshie, T.; Vučković, J.; Scherer, A.; Chen, H.; Deppe, D. High quality two-dimensional photonic crystal slab cavities. Appl. Phys. Lett. 2001, 79, 4289-4291. [CrossRef]

12. Wang, B.; Dündar, M.A.; Nötzel, R.; Karouta, F.; He, S.; van der Heijden, R.W. Photonic crystal slot nanobeam slow light waveguides for refractive index sensing. Appl. Phys. Lett. 2010, 97, 151105. [CrossRef]

13. Yang, D.; Tian, H.; Ji, Y.; Quan, Q. Design of simultaneous high-Q and high-sensitivity photonic crystal refractive index sensors. J. Opt. Soc. Am. Opt. Phys. 2013, 30, 2027-2031. [CrossRef]

14. Kuznetsov, A.I.; Miroshnichenko, A.E.; Brongersma, M.L.; Kivshar, Y.S.; Luk'yanchuk, B. Optically resonant dielectric nanostructures. Science 2016, 354. [CrossRef]

15. Lawrence, M.; Barton, D.R.; Dixon, J.; Song, J.H.; Dionne, J.A. High quality factor phase gradient metasurfaces. Nat. Nanotechnol. 2020, 15, 56-961. [CrossRef] [PubMed]

16. Akahane, Y.; Asano, T.; Song, B.S.; Noda, S. High-Q photonic nanocavity in a two-dimensional photonic crystal. Nature 2003, 425, 944-947. [CrossRef] [PubMed]

17. Song, B.S.; Noda, S.; Asano, T.; Akahane, Y. Ultra-high- Q photonic double-heterostructure nanocavity. Nat. Mater. 2005, 4, 207-210. [CrossRef]

18. Sharon, A.; Rosenblatt, D.; Friesem, A.A. Narrow spectral bandwidths with grating waveguide structures. Appl. Phys. Lett. 1996, 69, 4154. [CrossRef]

19. Fehrembach, A.L.; Sentenac, A. Unpolarized narrow-band filtering with resonant gratings. Appl. Phys. Lett. 2005, 86, 121105. [CrossRef]

20. Hong, Q.; Chen, X.; Zhang, J.; Zhu, Z.; Qin, S.; Yuan, X. Remarkably high-Q resonant nanostructures based on atomically thin two-dimensional materials. Nanoscale 2019, 11, 23149-23155. [CrossRef]

21. Inoue, T.; Zoysa, M.D.; Asano, T.; Noda, S. Realization of narrowband thermal emission with optical nanostructures. Optica 2015, 2, 27. [CrossRef]

22. Yu, G.; Fan, S. Narrowband thermal emission from a uniform tungsten surface critically coupled with a photonic crystal guided resonance. Opt. Express 2016, 24, 29896.

23. Li, P.; Taubner, T. Broadband Subwavelength Imaging Using a Tunable Graphene-Lens. ACS Nano 2012, 6, 10107-10114. [CrossRef] [PubMed]

24. Kong, X.T.; Khan, A.A.; Kidambi, P.R.; Deng, S.; Yetisen, A.K.; Dlubak, B.; Hiralal, P.; Montelongo, Y.; Bowen, J.; Xavier, S.; et al. Graphene-Based Ultrathin Flat Lenses. ACS Photonics 2015, 2, 200-207. [CrossRef]

25. Xia, F.; Mueller, T.; Lin, Y.m.; Valdes-Garcia, A.; Avouris, P. Ultrafast graphene photodetector. Nat. Nanotechnol. 2009, 4, 839-843. [CrossRef]

26. Lopez-Sanchez, O.; Lembke, D.; Kayci, M.; Radenovic, A.; Kis, A. Ultrasensitive photodetectors based on monolayer MoS2. Nat. Nanotechnol. 2013, 8, 497-501. [CrossRef] [PubMed]

27. Yao, Z.; Lu, M.; Zhang, C.; Wang, Y. Dynamically tunable and transmissive linear to circular polarizer based on graphene metasurfaces. J. Opt. Soc. Am. B 2019, 36, 3302-3306. [CrossRef]

28. Danaeifar, M.; Granpayeh, N. Graphene-based polarization-sensitive metasurfaces for integrated optics applications. Appl. Opt. 2020, 59, 10541-10546. [CrossRef]

29. Liu, K.; Zhang, J.F.; Xu, W.; Zhu, Z.H.; Guo, C.C.; Li, X.J.; Qin, S.Q. Ultra-fast pulse propagation in nonlinear graphene/silicon ridge waveguide. Sci. Rep. 2015, 5, 16734. [CrossRef] [PubMed]

30. Gholipour, B. The promise of phase-change materials. Science 2019, 366, 186-187. [CrossRef]

31. Abdollahramezani, S.; Hemmatyar, O.; Taghinejad, H.; Krasnok, A.; Kiarashinejad, Y.; Zandehshahvar, M.; Alù, A.; Adibi, A. Tunable nanophotonics enabled by chalcogenide phase-change materials. Nanophotonics 2020, 9, 1189-1241. [CrossRef]

32. Delaney, M.; Zeimpekis, I.; Du, H.; Yan, X.; Banakar, M.; Thomson, D.J.; Hewak, D.W.; Muskens, O.L. Nonvolatile programmable silicon photonics using an ultralow-loss Sb2Se3 phase change material. Sci. Adv. 2021, 7, eabg3500. [CrossRef]

33. Qu, Y.; Li, Q.; Cai, L.; Pan, M.; Ghosh, P.; Du, K.; Qiu, M. Thermal camouflage based on the phase-changing material GST. Light Sci. Appl. 2018, 7, 26. [CrossRef] [PubMed]

34. Carrillo, S.G.C.; Trimby, L.; Au, Y.Y.; Nagareddy, V.K.; Rodriguez-Hernandez, G.; Hosseini, P.; Ríos, C.; Bhaskaran, H.; Wright, C.D. A Nonvolatile Phase-Change Metamaterial Color Display. Adv. Opt. Mater. 2019, 7, 1801782. [CrossRef]

35. Liu, H.; Dong, W.; Wang, H.; Lu, L.; Ruan, Q.; Tan, Y.S.; Simpson, R.E.; Yang, J.K.W. Rewritable color nanoprints in antimony trisulfide films. Sci. Adv. 2020, 6, eabb7171. [CrossRef] 
36. Hemmatyar, O.; Abdollahramezani, S.; Lepeshov, S.; Krasnok, A.; Brown, T.; Alu, A.; Adibi, A. Advanced Phase-Change Materials for Enhanced Meta-Displays. arXiv 2021, arXiv:2105.01313.

37. De Galarreta, C.R.; Alexeev, A.M.; Au, Y.Y.; Lopez-Garcia, M.; Klemm, M.; Cryan, M.; Bertolotti, J.; Wright, C. Nonvolatile Reconfigurable Phase hange Metadevices for Beam Steering in the Near Infrared. Adv. Funct. Mater. 2018, 28, 1704993.1-1704993.9. [CrossRef]

38. Gholipour, B.; Zhang, J.; MacDonald, K.F.; Hewak, D.W.; Zheludev, N.I. An all-optical, non-volatile, bidirectional, phase-change meta-switch. Adv. Mater. 2013, 25, 3050-3054. [CrossRef]

39. Gholipour, B.; Karvounis, A.; Yin, J.; Soci, C.; MacDonald, K.F.; Zheludev, N.I. Phase-change-driven dielectric-plasmonic transitions in chalcogenide metasurfaces. NPG Asia Mater. 2018, 10, 533-539. [CrossRef]

40. Ding, F.; Yang, Y.; Bozhevolnyi, S.I. Dynamic metasurfaces using phase-change chalcogenides. Adv. Opt. Mater. 2019, 7, 1801709. [CrossRef]

41. Xiao, S.; Wang, T.; Liu, T.; Zhou, C.; Jiang, X.; Zhang, J. Active metamaterials and metadevices: a review. J. Phys. D Appl. Phys. 2020, 53, 503002. [CrossRef]

42. Wang, Q.; Rogers, E.T.F.; Gholipour, B.; Wang, C.M.; Yuan, G.; Teng, J.; Zheludev, N.I. Optically reconfigurable metasurfaces and photonic devices based on phase change materials. Nat. Photonics 2016, 10, 60-65. [CrossRef]

43. Zhang, J.; Zhang, Y.; Hong, Q.; Xu, W.; Zhu, Z.; Yuan, X. Near-Infrared Rewritable, Non-Volatile Subwavelength Absorber Based on Chalcogenide Phase Change Materials. Nanomaterials 2020, 10, 1222. [CrossRef]

44. Abdollahramezani, S.; Hemmatyar, O.; Taghinejad, M.; Taghinejad, H.; Krasnok, A.; Eftekhar, A.A.; Teichrib, C.; Deshmukh, S.; El-Sayed, M.; Pop, E.; et al. Electrically driven programmable phase-change meta-switch reaching $80 \%$ efficiency. arXiv 2021, arXiv:2104.10381.

45. Thakur, S.; Semnani, B.; Safavi-Naeini, S.; Majedi, A.H. Experimental Characterization of the Ultrafast, Tunable and Broadband Optical Kerr Nonlinearity in Graphene. Sci. Rep. 2019, 9, 10540. [CrossRef] [PubMed]

46. Delaney, M.; Zeimpekis, I.; Lawson, D.; Hewak, D.W.; Muskens, O.L. A New Family of Ultralow Loss Reversible Phase-Change Materials for Photonic Integrated Circuits: Sb2S3 and Sb2Se3. Adv. Funct. Mater. 2020, 30, 2002447. [CrossRef]

47. Falkovsky, L.A. Optical properties of graphene. J. Phys. Conf. Ser. 2008, 129, 012004. [CrossRef]

48. Piper, J.; Fan, S. Total Absorption in a Graphene Monolayer in the Optical Regime by Critical Coupling with a Photonic Crystal Guided Resonance. ACS Photonics 2014, 1,347-353. [CrossRef]

49. Voshchinnikov, N.V.; Videen, G.; Henning, T. Effective medium theories for irregular fluffy structures: aggregation of small particles. Appl. Opt. 2007, 46, 4065-4072. [CrossRef]

50. Wang, S.S.; Magnusson, R. Theory and applications of guided-mode resonance filters. Appl. Opt. 1993, 32, 2606-2613. [CrossRef]

51. Greffet, J.J.; Carminati, R.; Joulain, K.; Mulet, J.P.; Mainguy, S.; Chen, Y. Coherent emission of light by thermal sources. Nature 2002, 416, 61-64. [CrossRef] [PubMed]

52. Liu, Z.S.; Tibuleac, S.; Shin, D.; Young, P.P.; Magnusson, R. High-efficiency guided-mode resonance filter. Opt. Lett. 1998, 23, 1556-1558. [CrossRef] [PubMed]

53. Sahoo, P.K.; Sarkar, S.; Joseph, J. High sensitivity guided-mode-resonance optical sensor employing phase detection. Sci. Rep. 2017, 7, 7607. [CrossRef]

54. Kim, Y.; Wu, P.C.; Sokhoyan, R.; Mauser, K.; Glaudell, R.; Kafaie Shirmanesh, G.; Atwater, H.A. Phase Modulation with Electrically Tunable Vanadium Dioxide Phase-Change Metasurfaces. Nano Lett. 2019, 19, 3961-3968. [CrossRef] [PubMed]

55. Zhang, Y.; Fowler, C.; Liang, J.; Azhar, B.; Shalaginov, M.Y.; Deckoff-Jones, S.; An, S.; Chou, J.B.; Roberts, C.M.; Liberman, V.; et al. Electrically reconfigurable non-volatile metasurface using low-loss optical phase-change material. Nat. Nanotechnol. 2021, 16, 661-666. [CrossRef]

56. Zhang, J.; Hong, Q.; Zou, J.; Meng, Q.; Qin, S.; Zhu, Z. Ultra-narrowband visible light absorption in a monolayer MoS2 based resonant nanostructure. Optics Express 2020, 28, 27608-27614. [CrossRef]

57. Rogers, C.; Piggott, A.Y.; Thomson, D.J.; Wiser, R.F.; Opris, I.E.; Fortune, S.A.; Compston, A.J.; Gondarenko, A.; Meng, F.; Chen, X.; et al. A universal 3D imaging sensor on a silicon photonics platform. Nature 2021, 590, 256-261. [CrossRef] 